\title{
Factors Affecting Micro Finance Credit Use of Women Entrepreneurs: The Case of Sodo Zuria Woreda, Wolaita Zone, Southern, Regional State, Ethiopia
}

\author{
Yisehak Ossa Jokka \\ Lecturer, College of Business and Economics, Wolaita Sodo University, Wolaita Sodo, Ethiopia
}

\begin{abstract}
Microfinance and credit for small and medium-sized enterprises, particularly for women are important for enhancing the social and economic impact on the woman. MFI can compensate for some of the weaknesses in capital markets and can help low-income woman entrepreneurs to improve their enterprises. The general objective of the study was to analyze factors affecting the amount of micro credit borrowing by women entrepreneurs in the study area of omo micro finance institution. A multistage sampling technique was employed to select 90 women entrepreneur borrowers from the omo micro finance institution. Both quantitative and qualitative data were collected from sampled rural women through interview. Both descriptive and econometric data analyses techniques were applied. The findings of this study showed that average amount of loan obtained by women borrowers was 4201.67 ETB in the area. The inferential statistics revealed that personal variables like age, family size and economic variables: monthly saving, annual income and collateral type were found to be significantly influencing the amount of women institutional borrowing in the study area. The study recommend that micro finance institutions to improve their service in terms of speedy release of loan, reducing interest rate from the existing 15 percent, accepting oily group collateral and not insisting immovable collateral and encourage saving.
\end{abstract}

Keywords: Women entrepreneur, microcredit, Micro finance institution.

DOI: $10.7176 /$ RJFA/10-15-04

Publication date: August $31^{\text {st }} 2019$

\section{Introduction}

Microcredit has been one framework adopted to address this problem. Its evolution reflects acknowledgement of credit market failures especially in the formal financial sector. There has been, therefore, a shift from the formal financial sector to microfinance which incorporates both savings and credit. Entrepreneurship is progressively recognized as a vital driver on economic growth, productiveness, creativity as well as career, which is generally recognized as being essential area of economic dynamism. Transforming thoughts directly into economic opportunities could be the definitive difficulty regarding entrepreneurship. Heritage ensures that economic improvement is been considerably advanced by realistic people who are entrepreneurial as well as revolutionary, able to make use of opportunities as well as ready to consider pitfalls (Hisrich, 2005). Role of entrepreneurship and an entrepreneurial culture in economic and social development have often been undervalued.

Considering the various challenges and obstacles facing Ethiopia women which include; capital inadequacy, unavailability of the required infrastructure, lack of collaterals, high interest rates, low literacy level, few number of lending institution, it could be concluded that women are usually discouraged from venturing into enterprise development (Hisrich and Brush, 1986).Women account for $53 \%$ of the total population of the woreda. Among the woman 70,000 are found to be in the productive class of women. Of them only $852(1.2 \%)$ could be able to access credit from financial institution engaged in their area and they create their own job or become entrepreneurs (sodo zuria woreda OMFI progress report, 2015/16).

\section{Objectives of the Study}

The general objective of the study was to investigate factors affecting micro credit use of entrepreneurs in sodo zuria woreda.

\subsection{Specific objectives of the Study}

The study aimed to achieve the following specific objectives:-

1. To identify socioeconomic and demographic characteristics of the women entrepreneurs in line with microcredit use in the area.

2. To determine factors affecting the amount microcredit use by women entrepreneurs in the area

\section{Methodology}

\subsection{Description of the Study Area}

Sodo Zuria is one of the woredas in the Southern Nations, Nationalities, and Peoples' Region of Ethiopia. Part of the Wolayita Zone, SodoZuria is bordered on the southwest by Offa, on the west by Kindo Koysha, on the 
northwest by Damot Sore, on the north by Boloso Sore, on the northeast by Damot Gale, on the east by Damot Weyde, and on the southeast by Humbo. Town of Sodo was separated from Sodo woreda. Sodo zuria is one of the woreda found in wolayta zone which is found at $384 \mathrm{~km}$ south from Addis Ababa, through Hosaina road .It located between 6.72-6.990 NN latitude and 37.59-37.86 EE Longitude.

\subsection{Sources and Methods Data Collection}

The sources of data were both primary and secondary. In this study, both primary and secondary data were utilized. The primary data were collected from the sample women borrowers (in the sample Kebeles) by using a structured interview schedule. Data on all personal, socio-economic, and institutional variables that are related to the microcredit borrowing were collected. Secondary data were gathered from the different records of Omo Microfinance; Woreda Finance and Economic Development

\subsection{Sampling Method and sampling detrimination}

The woreda contains 30 kebele, from which four kebeles were selected randomly and those Kebeles contained 318 women entrepreneurs who had borrowed from the Omo microfinance institution.

In order to determine sample size, Yamane formula was used

Hence, the formula will be as below:

$\mathrm{n}=\frac{\mathrm{N}}{1+\mathrm{N}(\mathrm{e})^{2}}$

Where $\mathrm{n}$ is the sample size, $\mathrm{N}$ is the population size and $\mathrm{e}$ is the level of precision.

$\mathrm{n}=\frac{318}{1+318(0.09)^{2}}=90$

\section{4 .Methods of Data Analysis}

Both descriptive and econometrics methods of data analysis were employed. Descriptive analysis was used to explain to assess the amount of microcredit use by women entrepreneurs from Omo microfinance institution. In econometrics methods of data analysis the multiple linear regression models was used to identify factors affecting the amount microcredit of women entrepreneurs from Omo micro finance institution.

\subsection{Econometrics Analysis: Multiple linear Regression Model}

Multiple Linear regression model is employed to account for (predict) the variance in the linear dependent variable based on linear combinations of interval, dichotomous, or dummy independent variables. Multiple regressions can establish that a set of independent variables explains a proportion of the variance in a dependent variable at a significance level.

Regression analysis can also be applied to study how a response variable $\mathrm{Y}$ is dependent on more than one regression variables and continuous. For this purpose, a model is adapted to the observations, which can explain $\mathrm{Y}$ from all the regression together. If there are ' $\mathrm{m}$ ' regressions $\mathrm{X} 1, \mathrm{X} 2 \ldots \mathrm{X} 13$, then the linear regression model for the observations is as follows:

For this purpose, a model is adapted to the observations, which explain Y from all the regression together. The linear regression model for the observations is as follows:

$\mathrm{Y}=\beta_{0}+\beta_{1} \mathrm{X}_{1}+\beta_{2} \mathrm{X}_{2}+\beta_{3} \mathrm{X}_{3}+\beta_{4} \mathrm{X}_{4}+\beta_{5} \mathrm{X}_{5}+\beta_{6} \mathrm{X}_{6}+\beta_{7} \mathrm{X}_{7}+\beta_{8} \mathrm{X}_{8}+\beta_{9} \mathrm{X}_{9}+\beta_{10} \mathrm{X}_{10}+\beta_{11} \mathrm{X}_{11}+$ $\beta_{11} x_{11}+\beta_{12} x_{12}+\beta_{13} x_{13} \quad U_{i}$---------------------------------------------------------------(2)

In this model $\beta 0+\beta 1 X 1+\beta 2 X 2+\ldots+\beta 13 X 13$ are systematic explanatory part of the Model and $E$ is the random (or unexplained) part of the model. The residual term $\mathrm{E}$ is again assumed to be normally distributed with expectation 0 and variance $0^{2}$.The unknown parameters $\beta o, \beta 1, \beta 13$ are called the regression coefficients. Multiple regression model shares all the assumptions of correlation, linearity of relationships, the same level of relationship throughout the range of the independent variable, interval or near- interval data, absence of outliers, and data whose range is not truncated. In addition, it is important that the model being tested is correctly specified. The exclusion of important causal variables or the inclusion of extraneous variables can change markedly the beta weights and hence the interpretation of the importance of the independent variables (Gujarati, 2004).

Here in this study the dependent variable is profitability of saving and credit cooperative and explanatory variables which affect the dependent variables mentioned and their expected sign is also explained.

Multiple regression model shares all the assumptions of correlation: linearity of relationships, the same level of relationship throughout the range of the independent variable, interval or near- interval data, absence of outliers, and data whose range is not truncated. In addition, it is important that the model being tested is correctly specified. The exclusion of important causal variables or the inclusion of extraneous variables can change markedly the beta 
weights and hence the interpretation of the importance of the independent variables (Gujarati, 2004).

\section{Results and Discussion}

The findings of descriptive statistics and econometric analysis involving independent variables as well as dependent variable are presented. In order to attain the desired objectives different socio economic and institutional variables were included in the multiple linear regression models.

4.1 The socioeconomic characteristics of the women entrepreneurs in line with microcredit use in the area. Table 1: Monthly saving of respondents $(\mathbf{n}=90)$

\begin{tabular}{lllllll}
\hline NO & Monthly saving in ETB & Frequency & Percentage & Average loan in birr & F'-test & Sig \\
\hline $\mathbf{1}$ & $100-300$ ETB & 31 & 34.5 & 3700.00 & & \\
$\mathbf{2}$ & $301-400$ ETB & 20 & 22.2 & 4000.00 & \\
$\mathbf{3}$ & $401-600$ ETB & 28 & 31.1 & 4250.00 & \\
$\mathbf{4}$ & $601-700$ ETB & 8 & 8.9 & 4300.00 & \\
$\mathbf{6}$ & $>701$ ETB & 3 & 3.3 & 5000.00 & \\
\cline { 1 - 3 } & & $\mathbf{9 0}$ & $\mathbf{1 0 0}$ & $\mathbf{4 2 0 1 . 6 7}$ & \\
\hline
\end{tabular}

** Significance level at $<5 \%$ level

Source: Field survey, 2017

As indicated in Table 1, 31(34.5\%) women save 100 - 300 ETB and the least number of respondents $3(3.3 \%)$ were saving above $701 \mathrm{ETB}$ and the rest $20(22.2 \%)$ and $28(31.1 \%)$ women saved saving range of $301-400$ ETB and 401 - 600 ETB respectively in the area. As per the data, MFI gave larger amount of loan to those women who saved higher amount of savings. This was statistically significant as confirmed by F-test at $<5 \%$ level. The result was found to be consistent with that of Kurut, (2004), who concluded that monthly income and savings of individuals increased the amount of borrowing.

Age

It one of the important demographic that influence woman entrepreneurs in credit use in the area Table: 2 Age and Borrowing $(\mathbf{n}=90)$

\begin{tabular}{|c|c|c|c|c|c|c|}
\hline NO & $\begin{array}{l}\text { Age Category } \\
\text { (years) }\end{array}$ & Frequency & Percentage & $\begin{array}{l}\text { Average loan } \\
\text { in birr }\end{array}$ & F-test & Sig \\
\hline 1. & $18-25$ & 24 & 26.7 & 4437.00 & & \\
\hline 2. & $26-33$ & 37 & 41.1 & 4524.00 & 40.96 & $0.000 * * *$ \\
\hline 3. & $34-41$ & 18 & 20 & 4256.00 & & \\
\hline 4. & $>42$ & 11 & 12.2 & 4128.00 & & \\
\hline Total & & 90 & 100 & 4201.67 & & \\
\hline
\end{tabular}

*** Significance level at $<1 \%$ level, $(\mathrm{n}=90)$

The overall average loan obtained by women borrowers was 4201.67 ETB. That means the age of the respondents significantly affected the amount of microcredit borrowing by women as confirmed by F-statistics of the study area. The study result was similar to that of Eunice Kyungay (2007) who found that age of the women affected the amount of borrowing.

Family size

The average family size of the sample members was 6.4 persons. This was above the national average, of only 5 family members. The results of the study are presented in Table 2'. It can be observed that, $71.1 \%$ of respondents had $4-5$ family members and $20 \%$ of respondents had family size $1-3$ members. Nearly $9 \%$ of respondents had family size of over 6 six members.

The family size is significant in borrowing as the higher family size may prompt the borrower to divert the loan money for consumption purpose. The data showed that higher family size got least amount of average loan. When the numbers of family increased at households' level, they borrowed small amount money from the MFI. The reason might also be the MFI might have the policy of lending smaller loan amount to borrowers with larger family size.

Table: 3 Family size of borrowers $(n=90)$

\begin{tabular}{cclllll}
\hline No & Family size & Frequency & Percentage & Average loan in birr & F-test & Sig level \\
\hline $\mathbf{1 .}$ & $1-3$ & 18 & 20.0 & 5437.00 & & \\
$\mathbf{2 .}$ & $4-5$ & 64 & 71.1 & 4353.50 & 45.3 & $\mathbf{0 . 0 0 0 * * *}$ \\
$\mathbf{2 .}$ & $>6$ & 8 & 8.9 & 3405.00 & & \\
\hline Total & & $\mathbf{9 0}$ & $\mathbf{1 0 0}$ & $\mathbf{4 2 0 1 . 7}$ & & \\
\hline
\end{tabular}

*** Significance level at $<1 \%$ level, $(\mathrm{n}=90)$

Family size significantly affected the average amount of loan taken by women in the study area. The significant F-test further confirmed that average borrowing varied significantly among different family size groups. The study output was similar to that of Bottomley A. (1975), who concluded that the number of members in a 
family limited the amount of borrowing.

Collateral

Collateral is a form of security that MFIs take before lending loan and that helps them to realize their loan in case of non-payment of loan by borrowers. This is more so for giving loan for unorganized entrepreneurs to mitigate their risk. The women in the study area were to offer collaterals in the form of: moveable, immoveable and personal to get loan from the MFI (Table 4).

Table: 4 Type of collateral and borrowing

$(\mathbf{n}=90)$

\begin{tabular}{cllllll}
\hline No & Collateral Type & Frequency & Percentage & Average loan in birr & F-test & Sig \\
\hline $\mathbf{1 .}$ & Moveable & 12 & 13.3 & 3825.00 & & \\
2. & Immoveable & 65 & 72.3 & 4433.80 & 8.52 & $0.000 * * *$ \\
3. & Personal & 13 & 14.4 & 3388.40 & & \\
4. & Total & 90 & 100 & 4201.60 & & \\
\hline
\end{tabular}

*** Significance level at $<1 \%$ level,

Source: field survey, 2017

The collaterals were in addition to group collateral in the form of mutual guarantee given by women in group. As per group collateral norm, if one member fails to pay the loan on time the rest of the member are obliged to pay the loan.

As seen in the table, about $65(72.3 \%)$ respondents provided immoveable property as collateral to micro finance institution to take loan and $12(13.3 \%)$ respondents provided moveable property for collateral to micro finance institution to take loan and the remaining 13(14.4) respondents provided personal collateral to take loan. F-test indicated that there was significant different among average loan amount obtained by different collateral methods. Those who had immovable collateral type got highest amount of loan of 4433.80 ETB per borrower. This study result disagreed with that of Minniti, M \& Arenius, P. (2003) who found that those who offered moveable property got higher loan from the MFIs.

As seen in the table, the most of the MFI customers $55(61.1 \%)$ were complaining about services delivery delay of three weeks by the MFI before releasing the loan. Similarly, 27 (31\%) respondents could get loan within 1 - 2 weeks. However, 8 (8.9\%) had to wait till month before getting the loan. This study result was similar to that of Hamdani (2010) who after thorough investigation of microfinance borrowers suggested that the time taken to provide loan from MFI should not be longer than one week. He further found out that when the time taken is more the demand for loan decreased.

4.2 Factors affecting the micro finance credit use by women entrepreneurs in the area.

The linear regression model result shows that out of 13 variables tested only five variables, namely age, collateral type, annual income, family size, monthly saving have significant effect on the quantum of use of credit The results are presented in Table 5.

Table: 5. The Multiple Linear Regression Model Result (Dep. Variable: amount credit from MFI)

\begin{tabular}{|l|l|l|l|l|}
\hline Explanatory Variable & B Coefficient & Std. Error & t-value & Sig. \\
\hline Constant) & 2610.117 & & & \\
\hline Age & -4.462 & -1.87 & 2.385 & $0.001^{* * *}$ \\
\hline Education & -9.626 & -111.93 & 0.086 & 0.931 \\
\hline Business Experience & -486.848 & -302.20 & 1.611 & 0.250 \\
\hline Livestock holding & 69.012 & 403.57 & 0.171 & 0.31 \\
\hline Collateral Type & 27.029 & 13.12 & 2.059 & $0.040^{* *}$ \\
\hline Annual income & 0.148 & 0.06 & 2.19 & $0.042^{* *}$ \\
\hline Type of Business & -491.057 & -296.17 & 1.658 & 0.102 \\
\hline Family size & -234.4 & -64.39 & 3.640 & $0.0045^{* * *}$ \\
\hline Land size & 93.786 & 146.54 & 0.640 & 0.524 \\
\hline Training & 44.658 & 149.85 & 0.298 & 0.032 \\
\hline Purpose of loan & 134.261 & 171.46 & 0.783 & 0.04 \\
\hline Monthly saving & 0.185 & 2.388 & $0.003^{* * *}$ \\
\hline R Square & $0.807=80.7$ percent & \\
\hline R Square Adj & $0.78 .2=78.2$ percent & \\
\hline Root Mean Square Error & 113.75 & & \\
\hline Mean of Response & 297.06 & & \\
\hline Observations & 90 & & \\
\hline
\end{tabular}




\subsubsection{Interpretation of Regression Results}

The linear regression model result shows that out of 13 variables tested only five variables, namely age, collateral type, annual income, family size, monthly saving have significant effect on the quantum of borrowing. The results are presented in above tabele.

The statistical significance variables were interpreted as follows:

Age (AG): Age was found to be significantly affecting the amount of borrowing. When the age of respondents increase the amount of microcredit use tended to decrease. This might be because of the precaution being observed by both the MFI and the borrower to lend / borrow less as the higher aged women's earning capacity would be lower. The study was consistent with Nyamsogoro.( 2010).

Family size (FS): The family size of the respondents was found to be significantly and negatively affecting the amount of microcredit use of women entrepreneurs in the area. When the women's family size increased she took less amount of microcredit. This might be because of higher household expenditure involved in larger family and consequent low household surplus for repaying the loan. The study was consistent with that of Namak.C (2003).

Annual income: Annual income of women entrepreneurs was found to be significantly and positively affecting the amount of microcredit use. That means when the annual income of women increased, the level of microcredit borrowing also increased. The study result was in with that of Dovi (2006).

Monthly saving (MS): Monthly saving of women entrepreneurs was found to be significantly and positively affect amount of the use from the MFI. The MFI takes savings as additional collateral and releases commensurate loan. Therefore, when the monthly savings increased, the level of microcredit borrowing also increased. The result was similar to that of Birgegaard (1993). .

Collateral Type: Collateral Type was found to be significantly and positively affecting the amount of the use from the MFI. When the collateral type was immovable property rather than personal or moveable collateral, the loan amount was higher for obvious reasons. The result found by Kobonyo(1999) was similar to that of the present study.

\section{CONCLUSION AND RECCOMENDATIONS CONCLUSION}

Microfinance and credit for small and medium-sized enterprises, including in rural areas, particularly for women are important for enhancing the social and economic impact of the financial sector.

The study was undertaken to identify the determinants of quantum of microcredit obtained by the women borrowers of Omo Microfinance institution (OMFI) in Sodo zuria Woreda, Southern Ethiopia. The data was collected from the 90 women borrowers of OMFI and analyzed using descriptive statistics. Also multiple linear regression model was employed to explain the determinants of microcredit loan borrowing by women.

The following 13 variables were included in the model: Age, Education, Family size, Business experience in number, Interest rate in number, Amount of borrowing in Birr, Purpose of loan, Annual Income, Land size, Training access, Livestock holding, collateral type , business type , Monthly savings, Attitude and Startup capital.

The linear regression model result showed that out of 13 variables tested only five variables, namely age, collateral type, annual income, family size, monthly saving had significant effect on the quantum of borrowing.

\section{RECCOMENDATIONS}

Based on the result of the study, the following recommendations are suggested:

$>\quad$ The borrowers had felt (just perception) that the interest rate was very high. Therefore, Omo microfinance institution of the area should adjust the optimal level of the interest rate to satisfy the women entrepreneurs.

$>$ Majority of women felt that the service delivery was poor and hence the MFI should enhance the speed of loan sanction to satisfy the borrowers.

$>\quad$ The MFI need to accommodate aged women and women with higher family size for giving optimum loan even by taking additional collateral.

$>$ The MFI shall encourage more savings as it helps to enhance the eligible loan amount.

The MFI shall also take into account personal and movable collateral equally with immovable collateral for sanctioning

\section{References}

Birgegaard, L,(1993) Microcredit and Micro business Development”, July 8, 2004, www.developmentgateway.org/microfinance (accessed 5 September 2004)

Dovi.E.(2006) Tapping women's entrepreneurship in Ghana: Access to credit, technology vital for breaking into manufacturing. Africa Renewal, United Nations,p.12.

Hisrich. R.D.,Peters,M.P.\&amp; Shepherd,D.A.(2005).Entrepreneurship. New York: McGraw-Hill Irwin.

Kobonyo(1999) "Maximizing the Outreach of Microfinance in Russia", Research and Impact Assessment; Terms 
of Reference for FORA (London:

kurut, (2004) Microfinance Investment Advisers, 2004: "Micro-enterprises",www.blueorchard.ch (accessed 21/9/04)

Minniti, M \&amp; Arenius, P. (2003) Minniti, M \&amp; Arenius, P. (2003). Women in Entrepreneurship the Entrepreneurial Advantage of Nations: First Annual Global Entrepreneurship Symposium, United Nations Headquarters, pp1-28

Namak .C(2003) Financial Sector of the World Bank Group, 2002, "Rural and Microfinance SMEs", www.worldbank.org (accessed 4/9/04) 